\title{
Propriedades físico-mecânicas de painéis aglomerados madeira-bambu
}

\author{
Physical mechanical properties of wood-bamboo particleboard
}

\section{Rafael Rodolfo de Melo ${ }^{I^{*}}$ Diego Martins Stangerlin ${ }^{I}$ Adilson Pacheco de Sousa ${ }^{\mathrm{I}}$ Pedro Henrique Gonzalez de Cademartori ${ }^{\text {II }}$ Eduardo Schneid $^{\text {III }}$}

\section{RESUMO}

Foram avaliadas as propriedades físico-mecânicas de painéis aglomerados produzidos com diferentes proporções de madeira (Eucalyptus grandis) e bambu (Bambusa vulgaris). Os painéis foram produzidos utilizando o adesivo ureia-formaldeído com a adição de 0, 25, 50, 75 e 100\% de bambu. Para cada tratamento, determinaram-se as propriedades físicas (massa especifica; teor de umidade; absorção de água e inchamento em espessura após 2 e 24 horas de imersão em água) e mecânicas (flexão estática; ligação interna; e arrancamento de parafusos). Os resultados obtidos indicaram que o acréscimo das partículas de bambu proporcionou uma redução significativa na qualidade dos painéis para os parâmetros avaliados, apresentando uma maior absorção de água e uma menor resistência à flexão estática e ao arrancamento de parafuso.

Palavras-chave: painéis de madeira, materiais lignocelulósicos, Bambusa vulgaris.

\section{ABSTRACT}

It was evaluated the physical and mechanical properties of particleboard produced with different proportions of wood (Eucalyptus grandis) and bamboo (Bambusa vulgaris). The boards were produced using urea-formaldehyde adhesive with the addition of 0, 25, 50, 75 and 100\% of bamboo. For each treatment were determined physical properties (specific gravity, moisture content, water absorption and thickness swelling after 2 and 24 hours water immersion) and mechanical properties (static bending, internal bond and screw withdrawal). The results indicated that the addition of particles of bamboo provided a significant reduction in the quality of panels for most parameters, showing higher water absorption and a lower resistance to static bending and screw withdrawal.

Key words: wood panel, lignocellulosic materials, Bambusa vulgaris.

\section{INTRODUÇÃO}

A crescente demanda por matéria-prima para produção de compósitos tem feito com que inúmeros pesquisadores, dentre eles, HIZIROGLU et al. (2005), CALEGARI et al. (2007), MELO et al. (2009; 2010), STANGERLIN et al. (2011), venham buscando alternativas para substituir ou complementar a madeira na manufatura destes produtos. A mescla de partículas de madeira com outros materiais lignocelulósicos para produção de painéis objetiva a redução nos custos de obtenção da matéria-prima e pode ser empregada em escala industrial, desde que não sejam alteradas negativamente as propriedades físico-mecânicas destes produtos.

Além da madeira, os painéis aglomerados podem ser produzidos por outras fontes de fibras e, dentre estas, a utilização do bambu como fonte de matéria-prima tem apresentado grande destaque, devido as suas excelentes propriedades físicomecânicas (ARAÚJO et al., 2011; ARRUDA et al., 2011), já sendo empregado em escala industrial em diversos países asiáticos, como China, Índia, Tailândia, Vietnã e Malásia (KASIM et al., 2001; CHENG et al. 2006). No Brasil, apesar da diversidade de gêneros (34) e de espécies (232, sendo 174 endêmicas), o potencial dos bambus tem sido pouco explorado (ARRUDA et al., 2011).

O uso do bambu como componente na manufatura de painéis aglomerados demonstrou-se

\footnotetext{
Instituto de Ciências Agrárias e Ambientais (ICAA), Universidade Federal de Mato Grosso (UFMT), 78557-267, Sinop, MT, Brasil. E-mail: rrmelo2@yahoo.com.br.*Autor para correspondência.

IIPrograma de Pós-graduação em Engenharia Florestal (PPGEF), Universidade Federal do Paraná (UFPR), Curitiba, PR, Brasil.

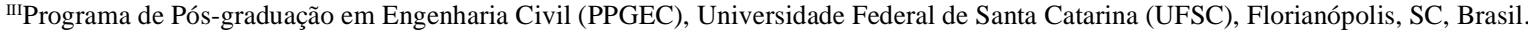
Recebido 10.10.12 Aprovado 03.06.14 Devolvido pelo autor 26.08.14 CR-2012-0970.R2
} 
eficiente em estudos realizados por PAPADOPOULOS et al. (2004) e ARRUDA et al. (2011). Já CALEGARI et al. (2007) verificaram, para painéis produzidos com partículas de bambu consorciadas com Eucalyptus sp., que, embora os painéis não tenham apresentado as exigências estabelecidas pelas normas, o uso do bambu mostrou-se uma alternativa viável para a produção de painéis aglomerados, uma vez que se comportou de maneira similar aos painéis produzidos exclusivamente com partículas de madeira.

Embora a avaliação do consórcio de partículas de bambu com partículas de madeira para produção de painéis aglomerados tenha sido objeto de estudo de diversos autores, a definição de um percentual ideal desta mistura, de modo que se obtenha um produto com as melhores características possíveis, ainda tem sido pouco estudada. No presente trabalho, foram avaliadas as propriedades físico-mecânicas de painéis aglomerados produzidos utilizando diferentes proporções de partículas de madeira (Eucalyptus grandis) e bambu (Bambusa vulgaris).

\section{MATERIAL E MÉTODOS}

A manufatura dos painéis foi realizada ao utilizar partículas de madeira de eucalipto e bambu. Para tanto, a matéria-prima foi obtida de seis árvores e 30 colmos de bambu foram obtidos em povoamentos homogêneosno município de Santa Maria, RS.As partículas de madeira (Eucalyptus grandis W. Hill ex Maiden) foram obtidas de árvores de povoamentos florestais homogêneos de aproximadamente 15 anos. Já os colmos de bambu (Bambusa vulgaris Schr.) foram obtidos em touceiras com aproximadamente quatro anos.

Os colmos de bambu foram cortados à altura média de $2 \mathrm{~m}$ da base, posteriormente, seccionados no sentido longitudinal e imersos em água, a fim de aumentar a exposição da sua face interna, para facilitar seu processo de trituração. Antes da trituração, foi removida a parte interna dos colmos. A trituração dos colmos foi realizada em moinho de martelos com a acoplagem de peneira com orifício de $3 \mathrm{~mm}$ de diâmetro, obtendo-se partículas de pequenas dimensões. Após secagem em estufa à temperatura de $60^{\circ} \mathrm{C}$, esse material foi peneirado em malhas de 4x4 e 1x1mm, com objetivo de melhor seleção do material e retirada dos finos, e então armazenados até o momento de manufatura dos painéis.

Depois de desdobradas, as árvores foram resserradas com cortes perpendiculares a grã, para obtenção de blocos de $5 \times 7 \mathrm{~cm}$ (tangencial x longitudinal) e largura variável (radial), conforme o diâmetro e posição de obtenção das tábuas na tora, os quais foram imersos em água até a saturação, exceto por doze amostras, que foram levadas à câmara de climatização para determinação da massa específica aparente da madeira ( $12 \%$ de umidade). Os valores de massa específica da madeira foram utilizados posteriormente para o cálculo da taxa de compressão dos painéis (razão entre a massa específica do painel e a massa específica da madeira, ambas a 12\% de umidade).

Posteriormente, dos blocos de madeira saturados, foi feita a obtenção das lascas em moinho de facas (flaker), com corte ajustado para $0,55 \mathrm{~mm}$ de espessura, produzindo, assim, lascas com 50x70x0,55mm de largura, comprimento e espessura, respectivamente. As lascas de madeira foram secas e reduzidas a partículas em moinho de martelos, equipado com peneira com orifícios de $8,0 \mathrm{~mm}$ de diâmetro. As partículas produzidas foram selecionadas em peneira de malha 1,0x1,0mm, sendo aproveitadas as que ficaram retidas nesta.

Foram produzidos painéis com massa específica nominal pré-estabelecida em $0,70 \mathrm{gcm}^{-3}$, nas dimensões 50x50x0,95cm (largura, comprimento e espessura). O adesivo utilizado foi ureia-formaldeído, na proporção de $8 \%$ de sólidos com base na massa seca das partículas. Foi adicionado ainda $1 \%$ de parafina em forma líquida. Adesivo e parafina foram aplicados por meio de pistola acionada por compressor de ar em um tambor rotativo. Juntamente com estes, foi aplicada a água necessária para ajustar o teor de umidade do colchão para aproximadamente $12 \%$, necessário para o processo de solidificação do adesivo.

Gerada a massa do colchão, foi retirada uma pequena amostra de $50 \mathrm{~g}$ para a determinação do teor de umidade do colchão e, quando esta apresentava uma variação superior a $\pm 2 \%$ da estimada, o material era descartado e o processo repetido. Após, a massa de partículas foi levada a um molde de madeira, com as dimensões $50 \times 50 \times 20 \mathrm{~cm}$. Em seguida, foi feita a prensagem definitiva em prensa hidráulica, com a temperatura de $180^{\circ} \mathrm{C}$, com pressão de 3,0MPa. O tempo de abertura e fechamento da prensa foi de 20 e 40 segundos, respectivamente. Já o tempo de prensagem aplicado para promover a evaporação da água e a cura do adesivo foi de oito minutos, totalizando nove minutos de tempo total da prensagem. Após a confecção, os painéis foram dispostos em câmara climatizada $\left(20 \pm 3^{\circ} \mathrm{C}\right.$ e $65 \pm 1 \%$ de umidade relativa) até atingirem massa constante. Em seguida, foram retiradas as amostras para realização dos ensaios. Os painéis foram produzidos ao empregar cinco diferentes proporções de madeira 
e bambu, num total de 20 painéis aglomerados, quatro para cada tratamento.

Para avaliação das propriedades dos painéis aglomerados produzidos, foram realizados ensaios físicos (teor de umidade; massa específica; absorção d'água; inchamento em espessura) e mecânicos (flexão estática; arrancamento de parafusos; e ligação interna) adotando as recomendações da norma da American Society for Testing and Materials - ASTM D 1037 (2006). Os valores médios observados para as propriedades mecânicas foram comparados com os mínimos exigidos pela norma de comercialização americana da American National Standards Institute - ANSI 208.1 (1993). Para o inchamento em espessura os valores foram comparados com os exigidos pela norma do German Standards Committee - DIN 68761(1)-1961(3) (1971), uma vez que a norma ANSI não contempla essa especificação.

A influência da adição de partículas de bambu (variável dependente) nas propriedades físicomecânicas (variáveis independentes) dos painéis aglomerados foi avaliada por meio de análise de regressão. Os critérios adotados para a seleção dos modelos foram: maior coeficiente de determinação ajustado - $\mathrm{R}^{2}{ }_{\text {aj }}$; menor erro padrão da estimativa - $\mathrm{S}_{\mathrm{yx}}$; maior valor de F calculado; e maior probabilidade de significância do modelo.

\section{RESULTADOS E DISCUSSÃO}

Densidade da madeira/bambu

A massa específica básica média observada para a madeira de Eucalyptus grandis foi de $0,51 \mathrm{gcm}^{-3}$. Já para o bambu, a densidade básica média dos colmos foi de $0,63 \mathrm{gcm}^{-3}$. Estes valores de densidade proporcionaram as taxas de compressão decrescentes com a inclusão das partículas de bambu nos painéis, variando de 1,37 a $1,12 \mathrm{gcm}^{-3}$ para os diferentes tratamentos avaliados.

Propriedades físicas dos painéis

Os valores médios observados para massa específica dos painéis variaram entre 0,67 a $0,69 \mathrm{gcm}^{-3}$, valores um pouco abaixo do préestabelecido na manufatura dos painéis, que foi de $0,70 \mathrm{gcm}^{-3}$ (Figura 1). Esse resultado pode ser atribuído a diversos fatores, como perdas de aditivos (adesivo e parafina) no momento da aplicação, devido a sua aderência nos instrumentos utilizados (mangueira, pistola e tambor misturador), diferenças na massa específica e no teor de umidade das partículas. MELO \& DEL MENEZZI (2010) observaram resultados semelhantes para painéis produzidos com partículas de Eucalyptus grandis, em que os autores evidenciaram, para massa específica, resultados inferiores ao da massa específica nominal (préestabelecida). Variações de massa específica foram observadas entre tratamentos, entre painéis de um mesmo tratamento e até dentro de um mesmo painel. Entretanto, estas variações não foram significativas estatisticamente. Pequenas variações também foram observadas por MELO et al. (2009) ao produzirem painéis com partículas de madeira e casca de arroz. Segundo os autores, tais variações ocorrem devido o processo manual de manufatura dos painéis em laboratório, especialmente nas fases de montagem do colchão e/ou na adição do adesivo e outros aditivos.

$\mathrm{O}$ teor de umidade de equilíbrio médio observado para os painéis variou entre 9,8 e 10,2\%, valores abaixo do teor de umidade da câmara climática (12\%). Esse resultado corrobora com SILVA et al. (2006), que afirmam ser o teor de umidade de equilíbrio para produtos reconstituídos de madeira inferior ao da madeira sólida, quando expostos em condições de temperatura e umidade semelhante. Isto se deve a diferentes níveis de higroscopicidade, que, segundo os autores, é causado pela redução da madeira em partículas com posterior incorporação de aditivos, como adesivo, parafina, entre outros. Além desses, outro aspecto que contribui para a redução da higroscopicidade destes produtos é a utilização de altas temperaturas e pressão na consolidação final do painel, que são responsáveis pela degradação parcial das polioses, em particular dos grupos hidroxílicos, que atribuem caráter hidrofílico à madeira.

Os modelos ajustados para absorção de água as 2 e 24 horas indicaram que o aumento do percentual de partículas de bambu nos painéis proporcionou uma maior absorção de água a estes (Figura 2). CALEGARI et al. (2007) também observaram que painéis produzidos utilizando o consórcio madeira-bambu apresentaram uma maior absorção, quando comparados àqueles em que fora empregado exclusivamente madeira. Todavia, também foi evidenciado por estes autores que painéis produzidos com epiderme das partículas de bambu proporcionaram uma melhora significativa quanto a este parâmetro. Essa maior absorção de água para painéis com maior proporção de bambu pode estar relacionada às características anatômicas (elevada porosidade) e química (maior percentual de hemicelulose e extrativos) deste material. Adicionalmente, ressalta-se a influência do menor teor de lignina do bambu, quando comparado à madeira, constituinte químico que apresenta característica hidrofóbica. 


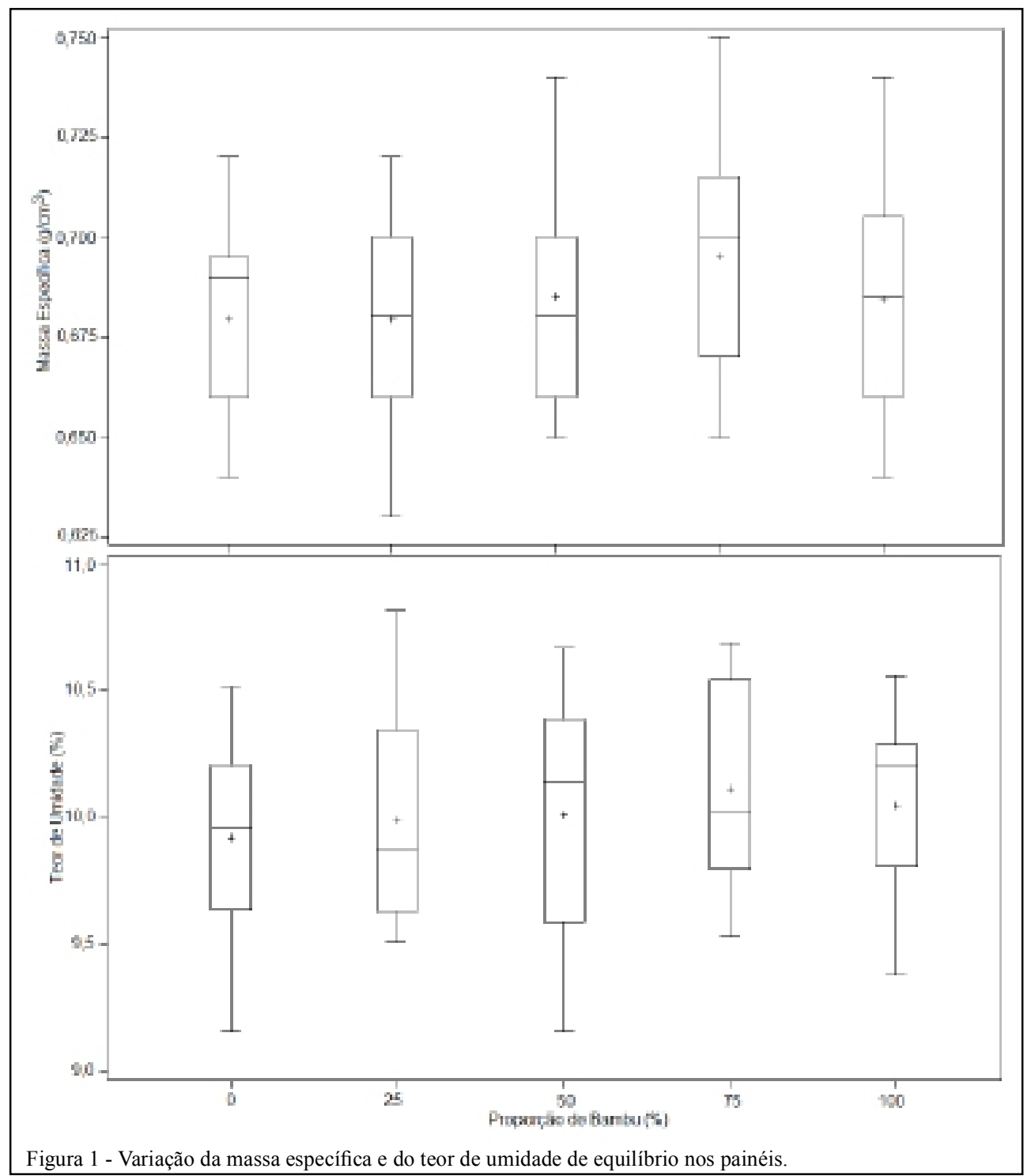

Para o inchamento em espessura, a inclusão das partículas de bambu nos painéis proporcionou perda em estabilidade em um momento inicial - logo após as duas horas de imersão. No entanto, ao se considerar o inchamento das amostras após 24 horas, não foi constatada tendência de aumento ou redução da estabilidade com o incremento das partículas de bambu nos painéis. Esse resultado pode ser atribuído à diferença entre a massa específica das partículas de madeira e bambu (PAPADOPOULOS, 2004). Embora painéis com maiores proporções de bambu tenham apresentado uma maior absorção de água, para o inchamento em espessura, uma maior liberação das tensões de compressão proporcionada pela menor massa específica das partículas de bambu podem ter influenciado na obtenção desse resultado.
MELO et al. (2009), ao estudarem a manufatura de painéis utilizando partículas de madeira e casca de arroz, verificaram que o aumento percentual da casca também proporcionou uma perda de qualidade nas propriedades físicas destes painéis (maiores absorção de água e inchamento em espessura). Além das características inerentes ao material utilizado, os autores atribuem este comportamento a dificuldades de interação das diferentes partículas no processo de colagem. Comportamento similar pode ter sido observado para os painéis produzidos com partículas de bambu e madeira.

Os percentuais de inchamento em espessura observados para todos os tratamentos, em média, atenderam as exigências da norma de comercialização da AMERICAN NATIONAL

Ciência Rural, v.45, n.1, jan, 2015. 

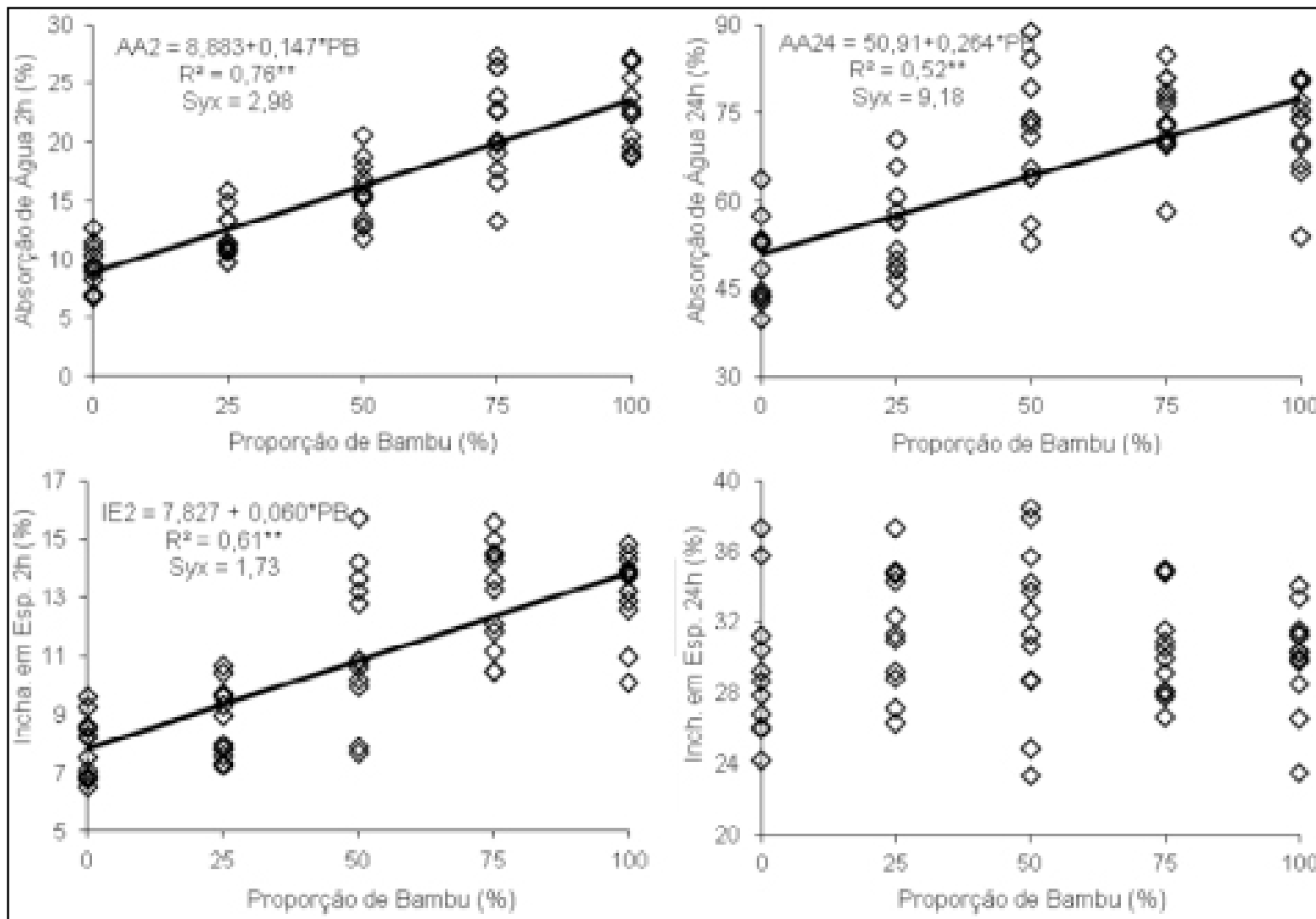

Figura 2 - Absorção de água e inchamento em espessura após 2 e 24 horas de imersão em função da proporção de bambu nos painéis (PB).

STANDARDS INSTITUTE - ANSI 208.1 (1993), que considera aceitáveis percentuais de absorção de até 35\% após 24 horas de imersão.

Propriedades mecânicas dos painéis

Os módulos de elasticidade (MOE) e ruptura (MOR) à flexão estática verificados para os painéis foram estimados com eficácia por meio da proporção de bambu utilizados na manufatura destes. Os resultados obtidos indicaram reduções na resistência e rigidez dos painéis com o aumento percentual das partículas de bambu (Figura 3). Diferente disso, CALEGARI et al. (2007), ao estudarem formas de partículas e métodos de montagem diferentes do presente estudo, não observaram influência na adição de partículas de bambu em painéis aglomerados produzidos com Eucalyptus sp. Já HIZIROGLU et al. (2005), ao estudarem painéis produzidos com diferentes proporções de Eucalyptus camaldulensis, palha de arroz e bambu, também observaram que a resistência mecânica de painéis mistos foi inferior, quando comparada aos painéis produzidos exclusivamente com partículas de madeira. Esse resultado pode ser atribuído pelos painéis produzidos exclusivamente com madeira apresentarem teoricamente maiores teores de celulose de que aqueles em que houve a adição do bambu (STANGERLIN et al., 2011). Essa característica química pode proporcionar um maior grau de polimerização e de cristalinidade, os quais interferem diretamente no aumento das propriedades mecânicas.

ARRUDA et al. (2011) verificaram que o incremento percentual de até $25 \%$ de partículas de bambu em painéis aglomerados não influenciaram no desempenho mecânico desses painéis. Resultados similares foram observados por MELO et al. (2009) ao avaliarem a produção de painéis utilizando partículas de madeira e casca de arroz. A norma ANSI 208.1 (1993) estabelece, como requisito mínimo para ensaios de flexão estática, uma exigência de 1.700MPa para o MOE e de 11MPa para o MOR. No presente estudo, essa exigência foi atendida pelos painéis produzidos exclusivamente com partículas de madeira, ou por aqueles que utilizaram em sua composição percentuais de até $50 \%$ de partículas de bambu.

$\mathrm{O}$ incremento das partículas de bambu nos painéis também proporcionou a redução da resistência ao arrancamento de parafuso (Figura 4). CALEGARI et al. (2007) não observaram diferença 


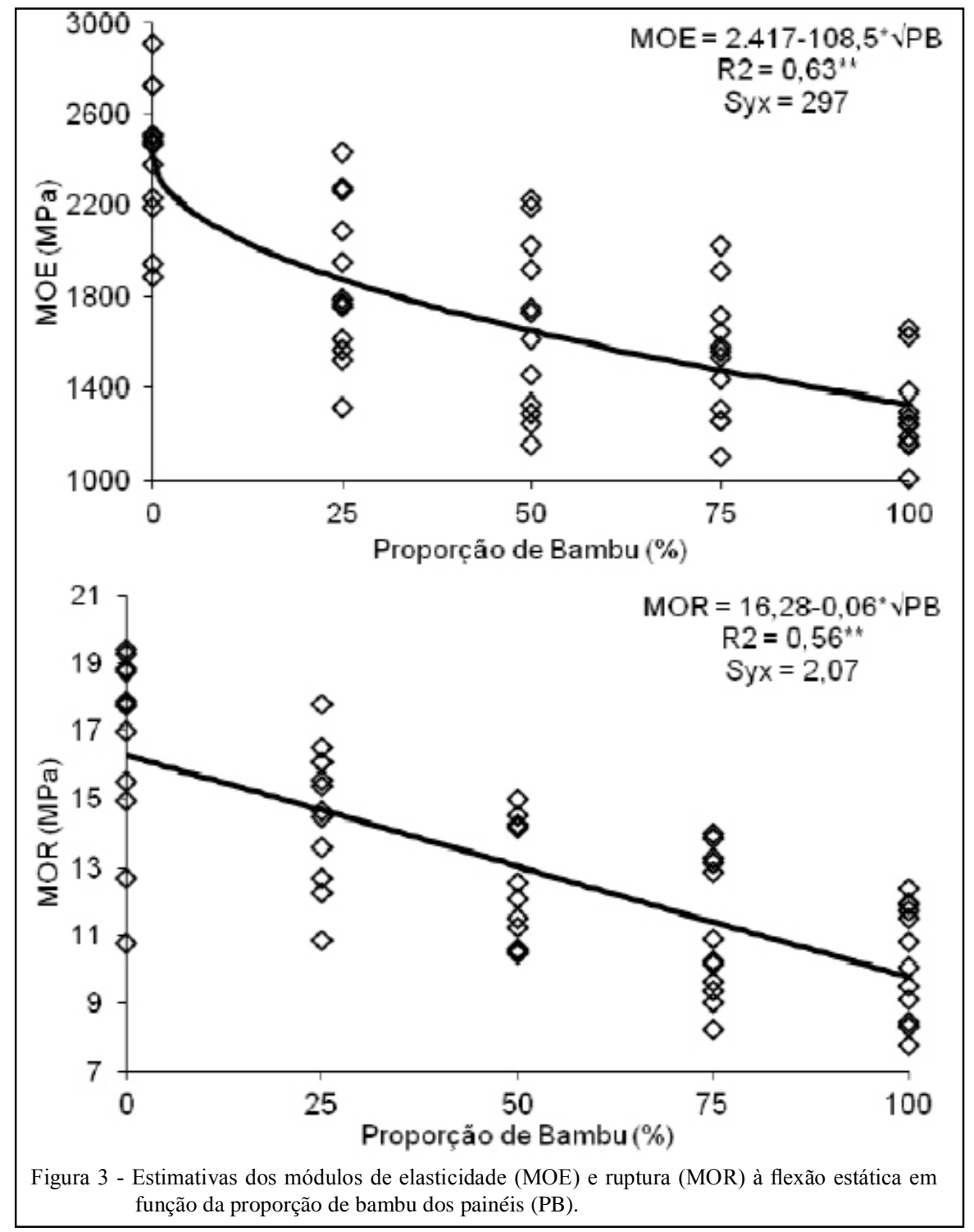

significativa neste parâmetro para as diferentes composições madeira-bambu avaliadas. Quanto à qualidade da colagem dos painéis, avaliada por meio da resistência à ligação interna, não foi influenciada pelas diferentes composições dos painéis, não sendo possível a geração de modelos para predição desta propriedade. HIZIROGLU et al. (2005) também verificaram em seu estudo que painéis produzidos exclusivamente com partículas de bambu, madeira ou com a mistura destas, não se diferenciaram estatisticamente quanto à resistência à ligação interna. Já CALEGARI et al. (2007) e ARRUDA et al. (2011) observaram que painéis confeccionados com maiores proporções de partículas de bambu apresentaram uma redução na resistência à ligação interna dos painéis.
A exigência quanto à resistência ao arrancamento de parafusos requerida para comercialização dos tipos de painéis avaliados é de aproximadamente 10N(ANSI 208.1, 1993). Desse modo, nenhum dos tratamentos avaliados apresentou valores superiores ou equivalentes aos exigidos. O mesmo caso ocorreu quando se avaliou o desempenho da ligação interna, quando nenhum dos tratamentos avaliados atingiu o valor estabelecido pela normativa, que é de cerca de 0,35 N (ANSI 208.1, 1993). PAPADOPOULOS et al. (2004) sugerem que, para atingir as rigorosas exigências da ANSI, painéis produzidos com partículas de bambu colados com UF devem utilizar teores de adesivo de aproximadamente $14 \%$, percentual que representa apenas cerca de

Ciência Rural, v.45, n.1, jan, 2015. 


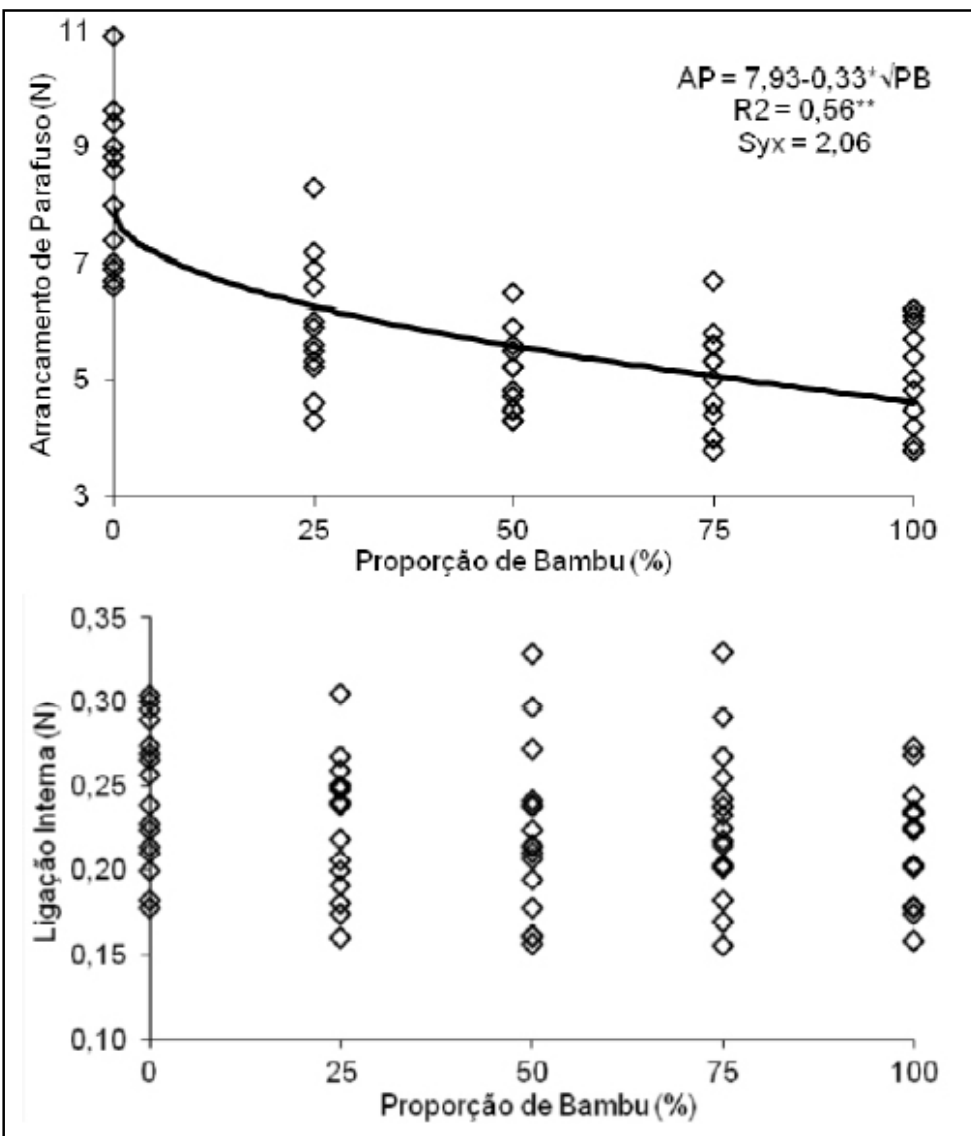

Figura 4 - Resistência ao arrancamento de parafuso (AP) e de ligação interna (LI) em função da proporção de bambu dos painéis (PB).

$60 \%$ do que foi empregado para produção dos painéis no presente estudo.

\section{CONCLUSÃO}

Os resultados obtidos indicam que as partículas de bambu apresentam potencial para serem utilizados como matéria-prima alternativa na composição de painéis aglomerados. $\mathrm{O}$ aumento do percentual de partículas de bambu proporcionou perda de qualidade nos painéis (aumento da absorção de água e redução da resistência a flexão e ao arrancamento de parafuso). Embora a utilização do bambu tenha proporcionado uma redução nos parâmetros qualitativos dos painéis, a composição de painéis mistos com partículas de madeirabambu, com uso de partículas de bambu em menor proporção, representando até metade da composição total de partículas do painel, pode ser possível à produção de painéis aglomerados com propriedades físico-mecânicas similares àquelas confeccionados exclusivamente com partículas de madeira.

\section{REFERÊNCIAS}

AMERICAN SOCIETY FOR TESTING AND MATERIALS (ASTM D 1037). Standard test methods for evaluating properties of wood-base fiber and particle panel materials. Philadelphia, 2006. 30p.

AMERICAN NATIONAL STANDARDS INSTITUTE (ANSI-A-208.1). Mat-formed wood particleboard. New York, 1993. 9 p.

ARRUDA, L.M. et al. Lignocellulosic composites from Brazilian giant bamboo (Guadua magna) Part 1: Properties of resin bonded particleboards. Maderas Ciencia y tecnologia, v.13, p.297306, 2011. Disponível em: <http://www.scielo.cl/pdf/maderas/ v13n1/ART05.pdf >. Acesso em: 15nov. 2011.doi10.4067/S0718$221 \times 2011000100005$.

CALEGARI, L. et al. Desempenho físico-mecânico de painéis fabricados com bambu (Bambusa vulgaris Schr.) em combinação com madeira. Cerne, v.13, p.57-63, 2007.Disponível em: <http:// redalyc.uaemex.mx/pdf/744/74413108.pdf>. Acesso em: 05 jan. 2012.

CHENG, J.L. et al. Nondestructiveevaluation techniques for assessing dynamic modulus of elasticityof moso bamboo (Phyllostachys edulis) lamina. Journalof Wood Science, v.52, p.342-347, 2006. Disponível em: <http://www.springerlink.com/ content/q3j50m14470153q3/fulltext.pdf $>$. Acesso em: 01 jun. 2012.doi10.1007/s10086-005-0772-1.

Ciência Rural, v.45, n.1, jan, 2015. 
HIZIROGLU, S. et al. Properties of bamboo-rice straw-eucalyptus composite panels. Forest Products Journal, v.55, p.221-225, 2005. Disponível em: <http://go.galegroup.com/ps/i.do?id=GALE $\% 7 C A 140795140 \& v=2.1 \& u=$ capes $58 \& \mathrm{it}=\mathrm{r} \& \mathrm{p}=\mathrm{AONE} \& \mathrm{sw}=\mathrm{w}>$. Acesso em: 28 jun. 2012.

GERMAN STANDARDS COMMITTEE. Deutschen Normanausschuss. Specifications for particleboards. Holtz, 1971. (DIN 68761 (1)-1961 (3)).

KASIM, J. et al. Properties of particleboard manufactured from commonly utilized Malaysian bamboo (Gigantochloa scortechinii). Pertanika Journalof Tropical Agricultural Science, v.24,p.151-157, 2001. Disponível em: <http://psasir.upm. edu.my/3342/1/properties_of_particleboard_manufactured_from_ commonly_utilized.pdf>. Acesso em: 25 jun. 2012.

MELO, R.R.; DEL MENEZZI, C.H.S. Influência da massa específica nas propriedades físico-mecânicas de painéis aglomerados. Silva Lusitana, v.18, p.59-73, 2010. Disponível em: <www.scielo.oces.mctes.pt/pdf/slu/v18n1/v18n1a04.pdf>. Acesso em: 28 jul. 2012.

MELO, R.R. et al. Resistência de painéis aglomerados produzidos com diferentes proporções de madeira e casca de arroz a fungos e cupins xilófagos. Ciência Florestal, v.20, p.501-511, 2010. Disponível em: <http://cascavel.ufsm.br/revistas/ojs-2.2.2/index.php/cienciaflorestal/ article/view/2064/1243>. Acesso em: 20 jun. 2012.

MELO, R.R. et al. Propriedades físico-mecânicas de painéis aglomerados produzidos com diferentes proporções de madeira e casca de arroz. Ciência Florestal, v.19, p.449-460, 2009. Disponível em: <http://cascavel.ufsm.br/revistas/ojs-2.2.2/index. php/cienciaflorestal/article/view/899/627>. Acesso em: 20 jun. 2012.

PAPADOPOULOS, A.N. et al. Bamboo chips (Bambusa vulgaris) as an alternative lignocellulosic raw material for particleboard manufacture. HolzalsRoh- undWerkstoff, v.62, p.36-39, 2004. Disponível em: <http://www.wfdt.teilar.gr/research.files/2004_06. pdf $>$. Acesso em:10 jun. 2012.

SILVA, G.A. et al. Estimativa de umidade de equilíbrio de painéis de madeira. Scientia Forestalis, n.70, p.23-29, 2006. Disponível em: $\langle$ http://www.ipef.br/publicacoes/scientia/nr70/cap02.pdf $\rangle$. Acesso em: 25 jun. 2012.

STANGERLIN, D.M. et al. Durabilidade natural de painéis aglomerados confeccionados com Eucalyptus grandis e Bambusa vulgaris em ensaio de apodrecimento acelerado. Ciência Rural, v.48, n.8, 1369-1374, 2011. Disponível em: <http://www.scielo. br/pdf/cr/v41n8/a8511cr3973.pdf >. Acesso em: 28 jun. 2012. doi10.1590/S0103-84782011000800012. 